\title{
Azomesogens with methoxyethyl tail: Synthesis and characterization
}

\author{
A K PRAJAPATI* and H M PANDYA \\ Applied Chemistry Department, Faculty of Technology and Engineering, MS University of Baroda, \\ Kalabhavan, P B No. 51, Vadodara 390 001, India \\ e-mail: akprajapati@yahoo.co.uk
}

MS received 9 March 2004; revised 11 January 2005

\begin{abstract}
Two new mesogenic homologous series are synthesized from methoxyethyl 4-(4'-hydroxyphenylazo) benzoate. In series I the phenolic -OH group is alkylated, whereas in series II it is esterified with 4- $n$-alkoxybenzoyl group. In series I, all the nine members synthesized exhibit only enantiotropic smectic A mesophase. In series II, all the twelve homologues exhibit enantiotropic nematic mesophase. Smectic A mesophase appears from the $n$-decyloxy derivative as a enantiotropic phase and persists till the last $n$-hexadecyloxy member. The mesomorphic properties of both the series are compared with each other and also with the properties of other structurally related series to evaluate the effect of the methoxyethyl tail on mesomorphism.
\end{abstract}

Keywords. Azomesogens; methoxyethyl tail; smectic A; nematic.

\section{Introduction}

Terminal substituents play a significant role in promoting liquid crystalline properties in a mesogen. The terminal substituents generally consist of either a homologue alkoxy or alkyl group or a compact unit such as nitro, cyano, halogen etc. ${ }^{1,2}$ A number of mesogenic homologous series of achiral esters with branched alkyl tail are also reported in the literature. ${ }^{3,4}$ However, a literature survey indicates that liquid crystalline esters with tails comprising different kinds of atoms are very rare. To distinguish these tail groups from branched alkyl groups, we will refer to them as broken alkyl terminal groups or chains. Weygand $e t a l^{5}$ have reported few compounds with alkyl chain combining two ether functions as a terminal substituent e.g. $\mathrm{CH}_{3} \mathrm{OCH}_{2} \mathrm{O}-$. They observed that the mesomorphic property disappears entirely or they have lower nematic thermal stabilities than the analogous compounds containing the group $\mathrm{CH}_{3} \mathrm{CH}_{2} \mathrm{CH}_{2} \mathrm{O}$ -

Later on Chiang et $a l^{6}$ studied effect of ethoxyethoxyethoxy and butoxyethoxyethoxy tails on mesomorphism. Earlier, we have reported ${ }^{7}$ three mesogenic homologous series of esters having methoxyethyl and ethoxyethyl tails. All the three mesogenic homologous series exhibited smectic A mesophase at ambient temperatures. We have also reported ${ }^{8}$ binary sys-

*For correspondence tems of such compounds with room temperature smectogenic properties and over a wide range of temperatures. Recently, we reported ${ }^{9}$ studies on the extensive mesogenic homologous series of Schiff's base esters having ethoxyethyl tails, which exhibited nematic and/or smectic mesophases with good thermal stabilities. We have therefore observed that such a broken alkyl chain at the terminus of a molecule adversely affects the mesophase thermal stability, but does not eliminate mesomorphism. In order to study further the effect of broken alkyl terminal chains on mesomorphism, two homologous series of azomesogens having methoxyethyl tails have been synthesized.

\section{Experimental}

\subsection{Characterization}

Microanalyses of the compounds were carried out on a Coleman carbon-hydrogen analyzer and the values obtained are in close agreement with those calculated. IR spectra were determined as $\mathrm{KBr}$ pellets, using a Shimadzu IR-408 spectrophotometer. ${ }^{1} \mathrm{H}$ NMR spectra were obtained with a Perkin-Elmer R-32 spectrometer using tetramethylsilane (TMS) as the internal reference standard. The chemical shifts are quoted as $\delta$ (parts per million) downfield from the reference. $\mathrm{CDCl}_{3}$ was used as a solvent for all 


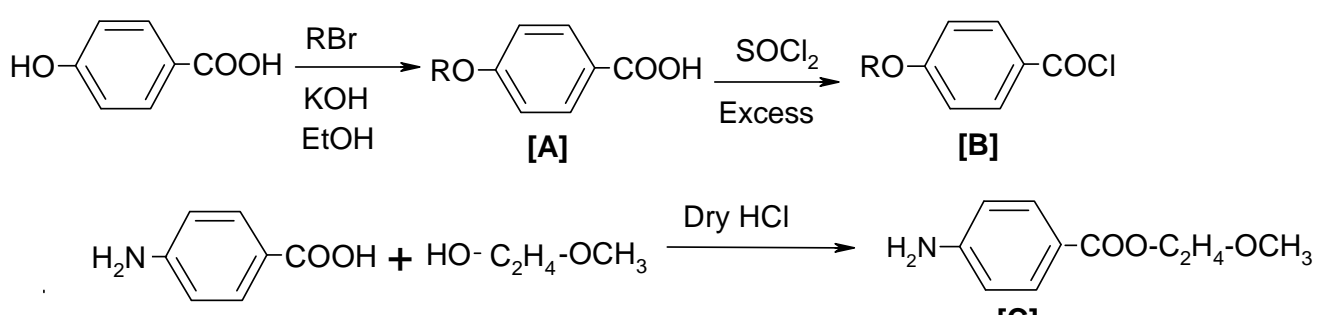

[C]

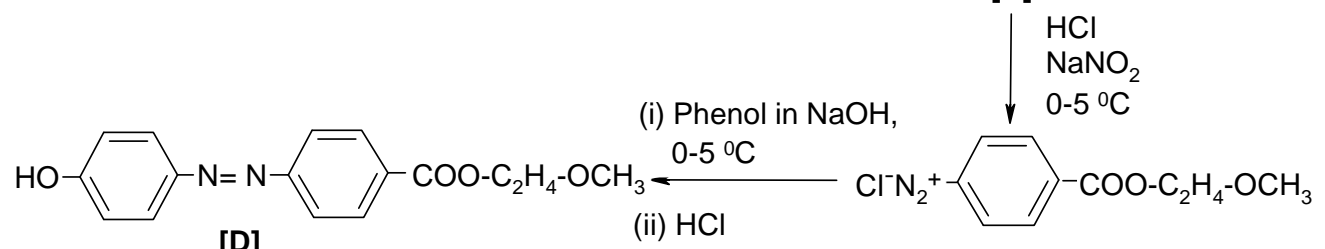

[D]

(ii) $\mathrm{HCl}$<smiles>[R]c1ccc(N=Nc2ccc(C(=O)OC)cc2)cc1</smiles>

[B] + [D] (i) Dry pyridine

(ii) $\mathrm{HCl}$

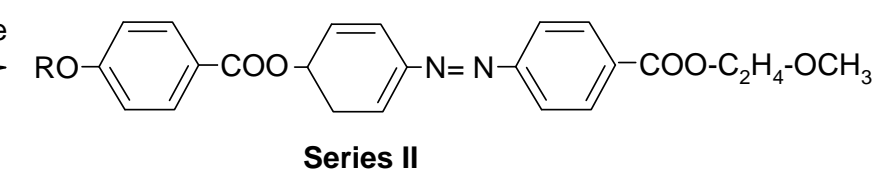

Scheme 1. Synthetic route to series I and II.

the compounds. Liquid crystalline properties were investigated on a Leitz Laborlux 12 POL microscope provided with a heating stage. The enthalpies of transitions reported as joules per gram, were determined from thermograms obtained on a Mettler TA-4000 system, adopting a scanning rate of $5^{\circ} \mathrm{C} / \mathrm{min}$. The calorimeter was calibrated using pure indium as standard.

\subsection{Synthesis}

4-Hydroxybenzoic acid, the appropriate $n$-alkyl bromides (BDH), 4-amino benzoic acid, 2-methoxyethanol, phenol, anhydrous $\mathrm{K}_{2} \mathrm{CO}_{3}$ and thionyl chloride (Sisco Chem.) were used as received. All the solvents were dried and distilled prior to use.

Compounds of the new series I and II were prepared following the pathway shown in scheme 1 .

$2.2 \mathrm{a}$ 4-n-Alkoxybenzoic acids (A) and 4-n-alkoxybenzoyl chlorides $(\boldsymbol{B})$ : These compounds were synthesized by a modified method. ${ }^{10}$ 2.2b Methoxyethyl-4-aminobenzoate $(\boldsymbol{C})$ : This was synthesized by the esterification of 4-aminobenzoic acid with 2-methoxyethanol as described earlier. $^{9}$

2.2c Methoxyethyl 4-(4'-hydroxyphenylazo) benzoate $(\boldsymbol{D})$ : The compound $\mathrm{D}$ was synthesized by using the diazotization of methoxyethyl 4-aminobenzoate and coupling it with phenol. ${ }^{11}$ The crude dye was crystallized repeatedly from aqueous ethanol till a constant melting point was obtained. m.p.: $212^{\circ} \mathrm{C}$. Elemental analysis: found $\mathrm{C} 63 \cdot 58, \mathrm{H} 5.96$, $\mathrm{N} 9.27 \%, \mathrm{C}_{16} \mathrm{H}_{18} \mathrm{~N}_{2} \mathrm{O}_{4}$ requires $\mathrm{C} 63.86, \mathrm{H} 5.79$, and $\mathrm{N} 9 \cdot 14 \%$. The IR spectrum of the compound showed a broad peak of intermolecular hydrogen-bonded phenolic -OH between 3500 and $3200 \mathrm{~cm}^{-1}$. The -COO- stretching vibrations were seen at $1690 \mathrm{~cm}^{-1}$. Other signals observed were at 1600, 1500, 1475, $1380,1240,1140,840 \mathrm{~cm}^{-1}$.

$2.2 \mathrm{~d}$ General procedure for synthesis of series I compounds: Compound D $(0.1 \mathrm{~mol})$, the appropri- 
Table 1. Elemental analysis for series I and II compounds.

\begin{tabular}{|c|c|c|c|c|c|}
\hline \multirow[b]{2}{*}{ Compound } & \multirow{2}{*}{$\begin{array}{c}\mathrm{R}=-\mathrm{C}_{n} \mathrm{H}_{2 n+1} \\
n=\end{array}$} & \multirow[b]{2}{*}{ Formula } & \multicolumn{3}{|c|}{$\%$ Required (\% found) } \\
\hline & & & $\mathrm{C}$ & $\mathrm{H}$ & $\mathrm{N}$ \\
\hline \multicolumn{6}{|l|}{ Series I } \\
\hline 1 & 4 & $\mathrm{C}_{20} \mathrm{H}_{24} \mathrm{~N}_{2} \mathrm{O}_{4}$ & $67 \cdot 41(67 \cdot 23)$ & $6 \cdot 74(6 \cdot 84)$ & $7 \cdot 86(7 \cdot 47)$ \\
\hline 2 & 5 & $\mathrm{C}_{21} \mathrm{H}_{26} \mathrm{~N}_{2} \mathrm{O}_{4}$ & $68 \cdot 11(6 \cdot 48)$ & $7 \cdot 03(7 \cdot 43)$ & $7 \cdot 57(7 \cdot 69)$ \\
\hline 3 & 6 & $\mathrm{C}_{22} \mathrm{H}_{28} \mathrm{~N}_{2} \mathrm{O}_{4}$ & $68 \cdot 75(68 \cdot 90)$ & $7 \cdot 29(7 \cdot 61)$ & $7 \cdot 29(6.93)$ \\
\hline 4 & 7 & $\mathrm{C}_{23} \mathrm{H}_{30} \mathrm{~N}_{2} \mathrm{O}_{4}$ & $69 \cdot 35(69 \cdot 48)$ & $7 \cdot 54(7 \cdot 52)$ & $7 \cdot 04(7 \cdot 41)$ \\
\hline 5 & 8 & $\mathrm{C}_{24} \mathrm{H}_{32} \mathrm{~N}_{2} \mathrm{O}_{4}$ & $69 \cdot 90(69 \cdot 74)$ & $7 \cdot 77(7 \cdot 53)$ & $6 \cdot 80(6 \cdot 74)$ \\
\hline 6 & 10 & $\mathrm{C}_{26} \mathrm{H}_{36} \mathrm{~N}_{2} \mathrm{O}_{4}$ & $70 \cdot 91(71 \cdot 20)$ & $8 \cdot 18(8 \cdot 46)$ & $6 \cdot 36(6 \cdot 18)$ \\
\hline 7 & 12 & $\mathrm{C}_{28} \mathrm{H}_{40} \mathrm{~N}_{2} \mathrm{O}_{4}$ & $71.79(71.62)$ & $8 \cdot 55(8 \cdot 54)$ & $5 \cdot 98(5 \cdot 81)$ \\
\hline 8 & 14 & $\mathrm{C}_{30} \mathrm{H}_{44} \mathrm{~N}_{2} \mathrm{O}_{4}$ & $72 \cdot 58(72 \cdot 42)$ & $8 \cdot 87(8 \cdot 69)$ & $5 \cdot 65(5 \cdot 48)$ \\
\hline 9 & 16 & $\mathrm{C}_{32} \mathrm{H}_{48} \mathrm{~N}_{2} \mathrm{O}_{4}$ & $73 \cdot 28(72 \cdot 38)$ & $9 \cdot 16(9 \cdot 38)$ & $5 \cdot 34(5 \cdot 65)$ \\
\hline \multicolumn{6}{|l|}{ Series II } \\
\hline 1 & 1 & $\mathrm{C}_{24} \mathrm{H}_{22} \mathrm{~N}_{2} \mathrm{O}_{6}$ & $66 \cdot 36(66 \cdot 48)$ & $5 \cdot 07(5 \cdot 17)$ & $6 \cdot 45(6 \cdot 82)$ \\
\hline 2 & 2 & $\mathrm{C}_{25} \mathrm{H}_{24} \mathrm{~N}_{2} \mathrm{O}_{6}$ & $66 \cdot 96(67 \cdot 16)$ & $5 \cdot 36(5 \cdot 31)$ & $6 \cdot 25(6 \cdot 55)$ \\
\hline 3 & 3 & $\mathrm{C}_{26} \mathrm{H}_{25} \mathrm{~N}_{2} \mathrm{O}_{6}$ & $67 \cdot 53(67 \cdot 12)$ & $5 \cdot 63(5 \cdot 71)$ & $6 \cdot 06(6 \cdot 27)$ \\
\hline 4 & 4 & $\mathrm{C}_{27} \mathrm{H}_{28} \mathrm{~N}_{2} \mathrm{O}_{6}$ & $68 \cdot 07(68 \cdot 35)$ & $5 \cdot 88(5 \cdot 91)$ & $5 \cdot 88(5 \cdot 72)$ \\
\hline 5 & 5 & $\mathrm{C}_{28} \mathrm{H}_{30} \mathrm{~N}_{2} \mathrm{O}_{6}$ & $68 \cdot 57(68 \cdot 46)$ & $6 \cdot 12(6 \cdot 48)$ & $5 \cdot 71(5 \cdot 92)$ \\
\hline 6 & 6 & $\mathrm{C}_{29} \mathrm{H}_{32} \mathrm{~N}_{2} \mathrm{O}_{6}$ & $69 \cdot 05(68 \cdot 76)$ & $6 \cdot 35(6 \cdot 83)$ & $5 \cdot 55(5 \cdot 64)$ \\
\hline 7 & 7 & $\mathrm{C}_{30} \mathrm{H}_{34} \mathrm{~N}_{2} \mathrm{O}_{6}$ & $69 \cdot 50(69 \cdot 84)$ & $6 \cdot 56(6 \cdot 87)$ & $5 \cdot 41(5 \cdot 08)$ \\
\hline 8 & 8 & $\mathrm{C}_{31} \mathrm{H}_{36} \mathrm{~N}_{2} \mathrm{O}_{6}$ & $69 \cdot 92(70 \cdot 04)$ & $6 \cdot 77(6 \cdot 48)$ & $5 \cdot 26(5 \cdot 37)$ \\
\hline 9 & 10 & $\mathrm{C}_{33} \mathrm{H}_{40} \mathrm{~N}_{2} \mathrm{O}_{6}$ & $70 \cdot 71(70 \cdot 58)$ & $7 \cdot 14(7 \cdot 02)$ & $5 \cdot 60(5 \cdot 79)$ \\
\hline 10 & 12 & $\mathrm{C}_{35} \mathrm{H}_{44} \mathrm{~N}_{2} \mathrm{O}_{6}$ & $71 \cdot 43(71 \cdot 88)$ & $7 \cdot 48(7 \cdot 52)$ & $4 \cdot 76(4 \cdot 41)$ \\
\hline 11 & 14 & $\mathrm{C}_{37} \mathrm{H}_{48} \mathrm{~N}_{2} \mathrm{O}_{6}$ & $72 \cdot 08(72 \cdot 17)$ & $7 \cdot 79(8.03)$ & $4 \cdot 54(4 \cdot 32)$ \\
\hline 12 & 16 & $\mathrm{C}_{39} \mathrm{H}_{52} \mathrm{~N}_{2} \mathrm{O}_{6}$ & $72 \cdot 67(72 \cdot 77)$ & $8 \cdot 67(8 \cdot 70)$ & $4 \cdot 35(4 \cdot 13)$ \\
\hline
\end{tabular}

ate $n$-alkyl bromide $(0.15 \mathrm{~mol})$ and anhydrous $\mathrm{K}_{2} \mathrm{CO}_{3}$ $(0.15 \mathrm{~mol})$ were added to dry acetone $(60 \mathrm{ml})$. The mixture was refluxed on a water bath for eight hours. The whole mass was then added to the water. The solid was separated, dried and triturated by stirring for 30 min with $10 \%$ aqueous sodium hydroxide solution and washed with water. The insoluble product was thus separated from the reactants. Finally, all the products were crystallized from ethanol till constant transition temperatures were obtained. Results of elemental analysis of all the compounds of series I were found to be satisfactory, and are listed in table 1 . IR and ${ }^{1} \mathrm{H}$ NMR spectral data of $n$-decyloxy derivative are given below.

IR spectrum $\left(i_{\max }, \mathrm{cm}^{-1}\right)$ : 2920, 1720 (-COO-), $1605(-\mathrm{N}=\mathrm{N}-), 1500,1465,1400,1255,1140,1020$, $845 \mathrm{~cm}^{-1}$.

${ }^{1} \mathrm{H}$ NMR $(200 \mathrm{MHz}): \delta 0.90\left(t, 3 \mathrm{H},-\mathrm{C}-\mathrm{CH}_{3}\right)$, $1.20-1.50\left(m, 16 \mathrm{H}, 8 \times-\mathrm{CH}_{2}-\right), 1.70-1.90(m, 2 \mathrm{H}$, $\left.\mathrm{PhO}-\mathrm{C}-\mathrm{CH}_{2}-\right), 3.45\left(s, 3 \mathrm{H},-\mathrm{OCH}_{3}\right), 3.75(t, 2 \mathrm{H}$, $\left.\mathrm{PhO}-\mathrm{CH}_{2}-\right), 4.05\left(t, 2 \mathrm{H},-\mathrm{COO}-\mathrm{C}-\mathrm{CH}_{2}-\right), 4.50(t$, $\left.2 \mathrm{H},-\mathrm{COOCH}_{2}-\right), 7.00(d, J=9 \mathrm{~Hz}, 2 \mathrm{H}, \mathrm{ArH}$ at C-3' and C-6'), 7.80-7.95 ( $m, 4 \mathrm{H}, \mathrm{ArH}$ at C-2', C-6', C3 and C-5), $8.20(d, J=9 \mathrm{~Hz}, 2 \mathrm{H}, \mathrm{ArH}$ at C-2 and C-6). 2.2e General procedure for synthesis of series II compounds: Compound D $(0.02 \mathrm{~mol})$ was dissolved in dry pyridine $(5 \mathrm{ml})$ and a cold solution of 4 - $n$-alkoxy benzoyl chloride $(0.02 \mathrm{~mol})$ in dry pyridine $(5 \mathrm{ml})$ was added slowly to it in an ice bath with constant stirring. The mixture was allowed to stand overnight at room temperature. It was acidified with cold $1: 1$ aqueous hydrochloric acid. The solid was separated, dried and triturated by stirring for 30 min with $10 \%$ aqueous sodium hydroxide solution and then washed with water. The insoluble product was thus separated from the reactants. Finally all the products were crystallized from acetic acid till constant transition temperatures were obtained. Elemental analyses of all compounds of series II were satisfactory and are listed in table 1. IR and ${ }^{1} \mathrm{H}$ NMR spectral data of n-tetradecyloxy derivative are given below.

IR spectrum $\left(i_{\max }, \mathrm{cm}^{-1}\right)$ : 2920, 1725 (-COO-), $1608(-\mathrm{N}=\mathrm{N}-), 1510,1415,1265,1172,1080,848$.

${ }^{1} \mathrm{H}$ NMR $(200 \mathrm{MHz}): \delta \quad 0.90\left(t, 3 \mathrm{H},-\mathrm{C}-\mathrm{CH}_{3}\right)$, $1.30-1.65\left(m, 22 \mathrm{H}, 11 \times-\mathrm{CH}_{2}-\right), 1.80-1.90(\mathrm{~m}, 2 \mathrm{H}$, $\left.\mathrm{PhO}-\mathrm{C}-\mathrm{CH}_{2}-\right), 3.45\left(s, 3 \mathrm{H},-\mathrm{OCH}_{3}\right), 3.78(t, 2 \mathrm{H}$, $\left.\mathrm{PhOCH}_{2}-\right), 4.05\left(t, 2 \mathrm{H},-\mathrm{COO}-\mathrm{C}-\mathrm{CH}_{2}-\right), 4.55(t$, 
Table 2. DSC data for series I and series II compounds.

\begin{tabular}{|c|c|c|c|c|c|}
\hline Series & $\begin{array}{c}\mathrm{R}=-\mathrm{C}_{n} \mathrm{H}_{2 n+1} \\
n=\end{array}$ & Transition & $\begin{array}{l}\text { Peak temperature } \\
\left({ }^{\circ} \mathrm{C}\right)\end{array}$ & $\begin{array}{c}\Delta H \\
\left(\mathrm{Jg}^{-1}\right)\end{array}$ & $\begin{array}{c}\Delta S \\
\left(\mathrm{Jg}^{-1} \mathrm{~K}^{-1}\right)\end{array}$ \\
\hline \multirow[t]{4}{*}{ I } & \multirow[t]{2}{*}{6} & $\mathrm{Cr}-\mathrm{Sm} \mathrm{A}$ & $66 \cdot 7$ & $21 \cdot 64$ & 0.0637 \\
\hline & & Sm A-I & $79 \cdot 3$ & $1 \cdot 38$ & 0.0039 \\
\hline & \multirow[t]{2}{*}{10} & $\mathrm{Cr}-\mathrm{Sm} \mathrm{A}$ & $75 \cdot 4$ & $19 \cdot 26$ & 0.0553 \\
\hline & & Sm A-I & $80 \cdot 1$ & $2 \cdot 17$ & 0.0062 \\
\hline \multirow[t]{6}{*}{ II } & \multirow[t]{3}{*}{10} & $\mathrm{Cr}-\mathrm{Sm} \mathrm{A}$ & $103 \cdot 2$ & $24 \cdot 35$ & 0.0647 \\
\hline & & Sm A-N & $164 \cdot 1$ & $0 \cdot 08$ & 0.0002 \\
\hline & & N-I & $229 \cdot 7$ & $1 \cdot 26$ & 0.0025 \\
\hline & \multirow[t]{3}{*}{14} & $\mathrm{Cr}-\mathrm{Sm} \mathrm{A}$ & 82.9 & $32 \cdot 41$ & $0 \cdot 0911$ \\
\hline & & Sm A-N & $156 \cdot 3$ & $1 \cdot 07$ & 0.0025 \\
\hline & & N-I & $219 \cdot 7$ & 0.09 & $0 \cdot 0002$ \\
\hline
\end{tabular}

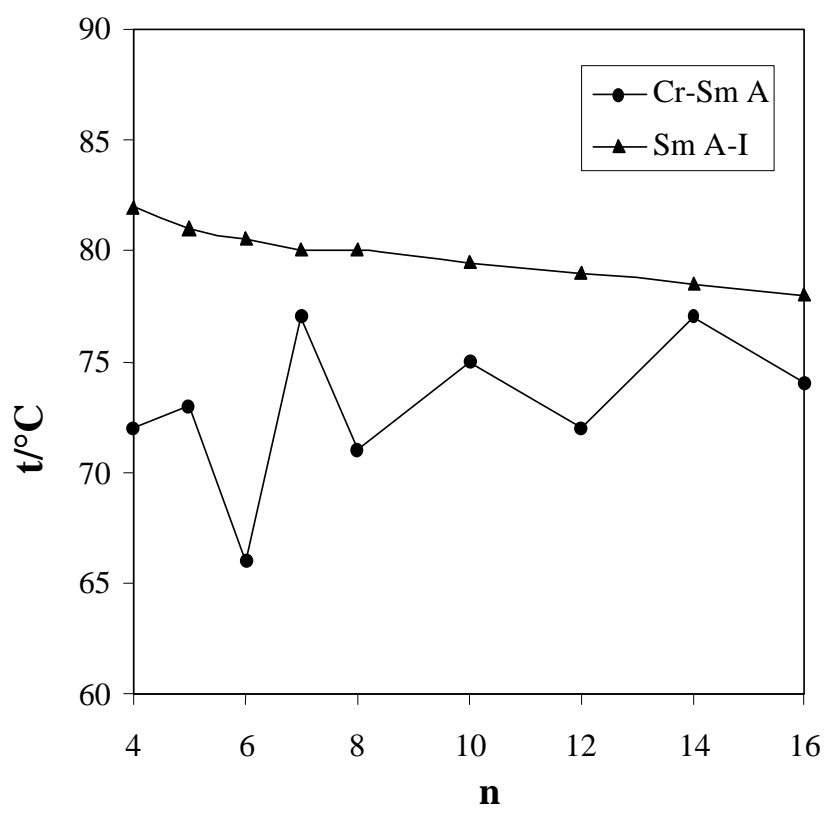

Figure 1. Phase behaviour of series I.

$\left.2 \mathrm{H},-\mathrm{COOCH}_{2}-\right), 7 \cdot 00(d, J=9 \mathrm{~Hz}, 2 \mathrm{H}, \mathrm{ArH}$ at C-3' and $\left.\mathrm{C}-5^{\prime}\right), 7.40(d, J=9 \mathrm{~Hz}, 2 \mathrm{H}, \mathrm{ArH}$ at $\mathrm{C} 3$ and $\mathrm{C}-5)$, 7.95-8.05 ( $m, 4 \mathrm{H}$, ArH at C-2, C-6, C-3" and C-5") 8.05-8.25 ( $m, 4 \mathrm{H}$, ArH at C-2', C-6', C-2" and C-6").

\section{Results and discussion}

As preliminary investigation, the mesophases exhibited by compounds of series I and II were examined by using an optical polarizing microscope. Thin films of the samples were obtained by sandwiching them between a glass slide and a cover slip. All the compounds of series I and II show mesomorphism. On cooling the isotropic liquid on an ordinary slide, focal-conic textures characteristic of the smectic A phase are observed for compounds of series I. In series II compounds, on cooling the isotropic liquid small droplets appear, which coalesce to classical schlieren (threaded) textures characteristic of the nematic phase. On further cooling, higher members (n 10) show focal-conic texture characteristic of the smectic A mesophase.

Calorimetry is a valuable method for the detection of phase transitions. It yields quantitative results; therefore we may draw conclusions concerning the nature of the phases which occur during the transitions. In the present study, enthalpies of two derivatives of each series I and II were measured by differential scanning calorimetry. Data are recorded in table 2. Enthalpy values of the various transitions agree well with the existing related literature values ${ }^{12}$ which fact has helped in further confirmation of the mesophase type.

\subsection{Series I: Methoxyethyl-4-(4'-n-alkoxyphenylazo) benzoates}

Nine compounds have been synthesized and their mesogenic properties are evaluated. All the compounds synthesized exhibit enantiotropic smectic A mesophase. The transition temperatures are recorded in table 3.

Plots of transition temperatures against the number of carbon atoms in the alkoxy chain (figure 1) show steady fall in smectic-isotropic transitions.

\subsection{Series II: Methoxyethyl [4-(4'-n-alkoxyben- zoyloxy) phenylazo]-4"-benzoates}

All the twelve members synthesized exhibit enantiotropic nematic mesophase. Smectic A mesophase 
appears from the $n$-butyloxy derivative as an enantiotropic phase and remains up to the $n$-hexadecyloxy derivative. The transition temperatures are recorded in table 4.

The entire homologous series II exhibit mesomorphism. The plot of transition temperatures against the number of carbon atoms in the alkoxy chain (figure 2) shows a smooth falling tendency for nematic-isotropic transition temperatures throughout the series. Series II also exhibit falling tendency of smectic-nematic transition temperatures for higher homologues. Table 5 summarizes the average mesophase range and average thermal stabilities as well as molecular structure of the present series I and II and the structurally related series $\mathrm{A},{ }^{7 \mathrm{a}} \mathrm{B}^{13}$ and $\mathrm{C}^{7 \mathrm{~b}}$ reported in the literature. Table 4 shows that series I exhibits only the smectic mesophase, whereas series

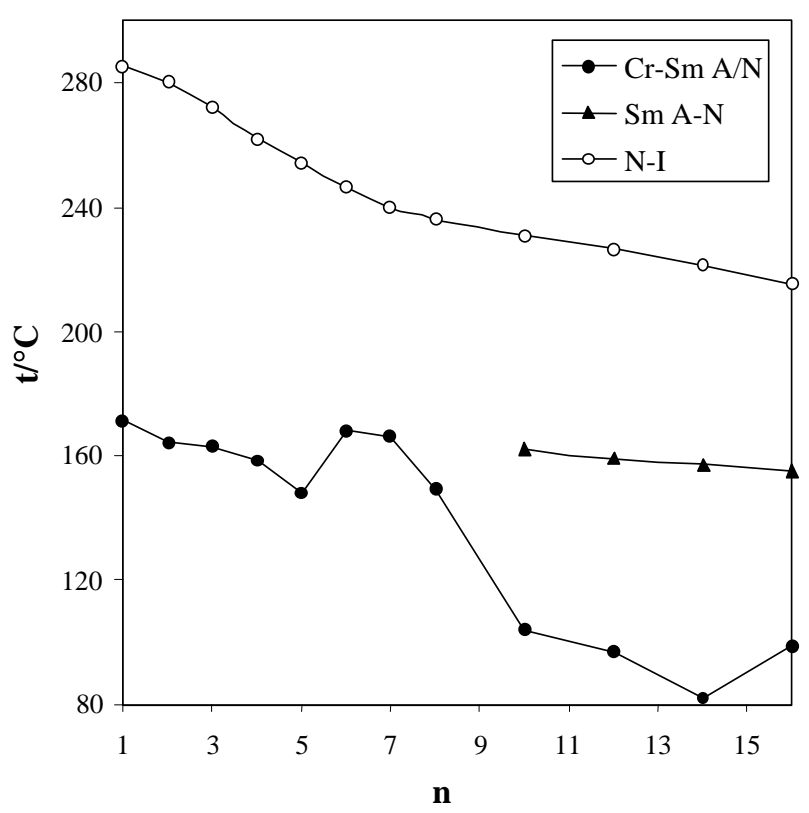

Figure 2. Phase behaviour of series II.

Table 3. Transition temperatures $\left({ }^{\circ} \mathrm{C}\right)$ of the series I.

\begin{tabular}{|c|c|c|c|c|c|c|}
\hline Compound & $n=$ & $\mathrm{Cr}$ & & $\mathrm{Sm} A$ & & I \\
\hline 1 & 4 & - & $72 \cdot 0$ & - & $82 \cdot 0$ & - \\
\hline 2 & 5 & - & $73 \cdot 0$ & - & $81 \cdot 0$ & - \\
\hline 3 & 6 & - & $66 \cdot 0$ & - & $80 \cdot 5$ & - \\
\hline 4 & 7 & - & $77 \cdot 0$ & - & $80 \cdot 0$ & - \\
\hline 5 & 8 & - & $71 \cdot 0$ & - & $80 \cdot 0$ & - \\
\hline 6 & 10 & - & $75 \cdot 0$ & - & 79.5 & - \\
\hline 7 & 12 & - & $72 \cdot 0$ & - & 79.0 & - \\
\hline 8 & 14 & - & $77 \cdot 0$ & - & $78 \cdot 5$ & - \\
\hline 9 & 16 & - & 74.0 & - & 78.0 & - \\
\hline
\end{tabular}

II exhibits smectic and/or nematic mesophases. Also the comparison of $n$-decyl to $n$-hexadecyl ethers in series I and II shows that the average relative mesophase length and thermal stabilities of the smectic phase in the series II are greater by $60.75^{\circ} \mathrm{C}$ and $79.50^{\circ} \mathrm{C}$ respectively compared to series I. The reference to molecular structure indicates that the molecules of series II are longer than the molecules of series I because of the third aromatic ring and a central ester linkage. Gray ${ }^{14}$ has explained that increase in the length of the molecules, as a result of its polarisability, increases the intermolecular cohesive forces which would be responsible for induction of nematic mesophase as well as the wider mesophase length and the higher average smectic thermal stabilities of series II molecules.

The smectic thermal stabilities of series I are higher as compared with those of the structurally related series A. Gray ${ }^{14}$ also defined that a compound which requires more thermal energy to disorganize the molecular arrangement of the smectic phase has greater smectic thermal stability. It can be seen from table 4 that more thermal energy has to be supplied to disorganize the molecular arrangement of the smectic phase of compounds of series I, as can be evidenced by the fact that the average Sm-I transition temperatures are higher by $8.00^{\circ} \mathrm{C}$ than those of compounds of series A. The slightly higher smectic thermal stabilities of series I may probably due to the presence of the $-\mathrm{N}=\mathrm{N}-$ central linkage which is more coplanar than the - $\mathrm{COO}-$ central linkage and allows packing of the molecules such that the smectic thermal stabilities of series I become higher than those of series A. The average smectic mesophase length of series I molecules are lower than those of series A. The thermal stability of a mesophase is a more important factor in relating mesomorphic behaviour to chemical constitution, since the temperature range of a mesophase may be determined partly by the unpredictable nature of the crystal-mesophase temperature.

Reference to table 5 indicates that the average width and thermal stabilities of the smectic mesophase of series I are lowered by $7.50^{\circ} \mathrm{C}$ and $13.75^{\circ} \mathrm{C}$ respectively, compared to series $\mathrm{B}$. The molecules of series I and series B differ only at one terminus. The $-\mathrm{OCH}_{3}$ terminal group of series I is replaced by $-\mathrm{CH}_{3}$ in series B. Weygand et $a l^{5}$ have studied an alkyl chain combining two ether functions, e.g. $\mathrm{CH}_{3} \mathrm{OCH}_{2} \mathrm{O}-$. Relatively few compounds have been examined, but the data show that the mesomorphic 
Table 4. Transition temperatures $\left({ }^{\circ} \mathrm{C}\right)$ of the series II.

\begin{tabular}{|c|c|c|c|c|c|c|c|c|}
\hline Compound & $n=$ & $\mathrm{Cr}$ & & $\mathrm{Sm} \mathrm{A}$ & & $\mathrm{N}$ & & I \\
\hline 10 & 1 & $\bullet$ & 171 & - & - & $\bullet$ & 285 & $\bullet$ \\
\hline 11 & 2 & $\bullet$ & 164 & - & - & $\bullet$ & 280 & • \\
\hline 12 & 3 & $\bullet$ & 163 & - & - & $\bullet$ & 272 & $\bullet$ \\
\hline 13 & 4 & - & 158 & $\bullet$ & - & $\bullet$ & 262 & $\bullet$ \\
\hline 14 & 5 & $\bullet$ & 148 & $\bullet$ & - & $\bullet$ & 254 & • \\
\hline 15 & 6 & • & 168 & $\bullet$ & - & $\bullet$ & 246 & $\bullet$ \\
\hline 16 & 7 & • & 166 & $\bullet$ & - & $\bullet$ & 240 & $\bullet$ \\
\hline 17 & 8 & $\bullet$ & 149 & $\bullet$ & - & $\bullet$ & 236 & - \\
\hline 18 & 10 & $\bullet$ & 104 & $\bullet$ & 162 & $\bullet$ & 231 & - \\
\hline 19 & 12 & • & 97 & $\bullet$ & 159 & $\bullet$ & 226 & • \\
\hline 20 & 14 & $\bullet$ & 82 & $\bullet$ & 157 & $\bullet$ & 221 & $\bullet$ \\
\hline 21 & 16 & • & 99 & $\bullet$ & 155 & • & 215 & $\bullet$ \\
\hline
\end{tabular}

Table 5. The average mesophase length, average thermal stabilities and molecular structure of series I, II, A, B and C.

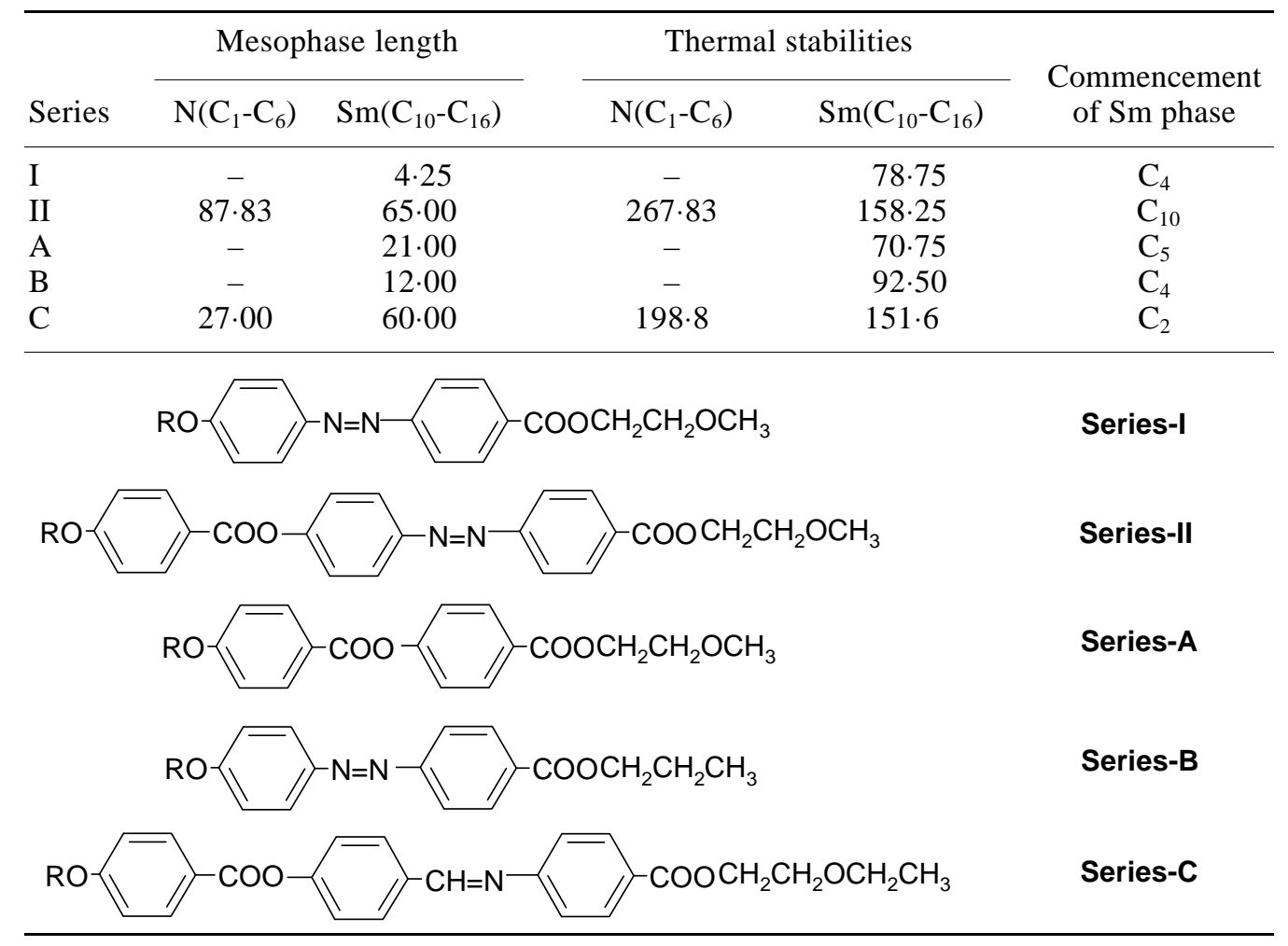

property disappears entirely or they have lower nematic thermal stabilities than the analogous compounds containing the $\mathrm{CH}_{3} \mathrm{CH}_{2} \mathrm{CH}_{2} \mathrm{O}$ - terminal substituent. Earlier, we ${ }^{7}$ have also observed that the broken alkyl chain at the terminus adversely affects mesophase thermal stabilities. In the present investigations also we have made the same observations.

Reference to table 5 also indicates that the average smectic and nematic mesophase length as well as thermal stabilities of present series II are higher than for series C. Both the series differ by the central linkage and the terminal chain. In series II there is an azo central linkage and methoxyethyl tail, whereas in series $\mathrm{C}$ there is an azomethine central linkage and ethoxyethyl tail. As an azo central linkage is more coplanar than an azomethine central linkage, probably the explanation given in the forgoing discussion would hold well in the comparison of these two series. Moreover, earlier also we ${ }^{7 a}$ have observed that ethoxyethyl mesophase thermal stabilities affects 
more adversely as compared to the methoxyethyl tail. However, data for more such series would help in understanding these trends.

\section{Conclusions}

In this article we have presented the synthesis and characterization of two new mesogenic homologous series of azobenzene derivatives containing ethoxyethyl tails, as azobenzene derivatives are more stable compared to Schiff base derivatives. Series I is purely smectogenic as it is a short two-phenyl rings system, whereas series II exhibit nematic as well as smectic A mesophases due to the presence of an additional phenyl ring along with an ester linkage. Though the broken alkyl tail is believed to be deterrent to mesomorphic behaviour, the compounds exhibit mesomorphic properties with good thermal stabilities if properly designed.

\section{Acknowledgements}

The authors thank Prof S M Joshi, and Dr N D Jadav for encouragement.

\section{References}

1. Demus D and Zaschke H 1984 Flussige Kristalle in Tabellen II (Leipzig: VEB Deutscher Verlag fur Grundstoffindustrie)
2. Kelker H 1980 Handbook of liquid crystals (eds) H Kelker and R Hatz (Weinheim: Verlag Chemie)

3. Gray G W and Harrison K J 1971 Mol. Cryst. Liq. Cryst. 13 37; Gray G W and Harrison K J 1971 Symp. Faraday Soc. (no. 5) 54; Gray G W and Kelly S M 1984 Mol. Cryst. Liq. Cryst. 104335

4. Matsunaga Y and Miyajima N 1984 Bull. Chem. Soc. Jpn. 57 1413; Matsunaga Y and Matsuzaki H 1990 Bull. Chem. Soc. Jpn. 63 2300; Matsunga Y, Matsuzaki H and Miyajima N 1990 Bull. Chem. Soc. Jpn. 63886

5. Weygand C, Gabler R and Bircon N 1941 J. Prakt. Chem. 158266

6. Chiang Y H, Ames A E and Nieman A 1998 Mol. Cryst. Liq. Cryst. 312 95; Chiang Y H, Ames A E, Gaudiana R A and Adams T G 1991 Mol. Cryst. Liq. Cryst. 20885

7. (a) Vora R A and Prajapati A K 1994 J. Mysore Univ. B 33A 61 (b) Vora R A and Prajapati A K 2001 Proc. Indian Acad. Sci. (Chem. Sci.), 11395

8. Prajapati A K, Vora R A and Patel M 1999/2000 J. MS Univ. Baroda 46/47(2) 87

9. Prajapati A K, Sharma H C and Chudgar N K 2001 Mol. Cryst. Liq. Cryst. 364815

10. Dave J S and Vora R A 1970 In Liquid crystals and ordered fluids (eds) J F Johnson and R S Porter (New York: Plenum) p. 477

11. Hanmann J and Koragov D 1996 Eur. Polym. J. 32 1437

12. Marzotko D and Demus D 1975 Pramana 1189

13. Jadav N D $1979 \mathrm{Ph}$ D thesis, M S University of Baroda, Vadodara

14. Gray G W 1962 In Molecular structure and properties of liquid crystals (London and New York: Academic Press) 